\title{
Correction to: The Need for Recovering the Subjugated Knowledge of Traditional Chinese Medicine
}

\author{
Lau Kin $\mathrm{Chi}^{1}$ · Sit Tsui ${ }^{2}$
}

Published online: 18 January 2021

๑) Society for International Development 2021

\section{Correction to: Development \\ https://doi.org/10.1057/s41301-020-00276-8}

Due to an unfortunate oversight the correspondence author of this article has been given incorrectly. It should be Sit Tsui. The original article has been corrected.

Publisher's Note Springer Nature remains neutral with regard to jurisdictional claims in published maps and institutional affiliations.

The original article can be found online at https://doi.org/10.1057/ s41301-020-00276-8.

Sit Tsui

sittsui@gmail.com

Lau Kin Chi

laukc@ln.edu.hk

1 Lingnan University, Hong Kong, China

2 Southwest University, Chongqing, China 